\title{
PEMBELAJARAN PADA MATA KULIAH ELEKTRONIKA DAYA: SUATU KAJIAN LITERATUR
}

\author{
Yahfizham ${ }^{1)}$, Kasman Rukun²), Krismadinata ${ }^{3)}$, Ganefri $^{4)}$, Sukardi'5), Nizwardi Jalinus ${ }^{6}$, \\ ${ }^{1}$ Fakultas IImu Tarbiyah dan Keguruan \\ 2,3,4,5,6Fakultas Teknik, \\ 1 Universitas Islam Negeri Sumatera Utara Medan \\ 2,3,4,5,6Universitas Negeri Padang \\ yahfizham@uinsu.ac.id, kasman.rukun@gmail.com,krisma@ft.unp.ac.id, ganefri@ft.unp.ac.id, \\ sukardi@ft.unp.ac.id,nizwardi@unp.ac.id
}

\begin{abstract}
Abstrak
Mata kuliah elektronika daya terdapat dalam kurikulum Pendidikan Teknologi dan Kejuruan di Indonesia, khususnya pada fakultas teknik elektro dan elektronika. Materi ajar yang terkandung didalamnya banyak digunakan sebagai bekal memasuki dunia usaha dan industri. Pesatnya perkembangan teknologi elektro dan elektronika menjadi tantangan tersendiri dalam mengajarkan mata kuliah ini. Disisi lain bahwa pertumbuhan teknologi informasi dan komunikasi (TIK) telah digunakan untuk mendukung kegiatan pembelajaran. Tujuan penulisan artikel untuk mengungkapkan berbagai macam masalah dan solusi terkait mata kuliah tersebut. Metode analisis deskriptif dilakukan dengan studi literatur yang diterbitkan mulai dari tahun 2011 sampai 2017. Kerangka konseptual strategi pengajaran elaborasi antara metode yang berpusat pada pendidik dengan metode yang berpusat pada mahasiswa memanfaatkan perangkat lunak sebagai suatu layanan (Software as a Service/ SaaS), coba untuk ditawarkan sebagai alternatif lain, sehingga diharapkan dapat dikembangkan menjadi suatu model pembelajaran.
\end{abstract}

Kata kunci: Elektronika Daya, Studi literatur, Pembelajaran, Integrasi Teknologi

\begin{abstract}
Power electronics course which was taught in the Technical and Vocational Education and Training (TVET) curriculum in Indonesian, especially at the department of electrical engineering. The applications contained in this subject was widely used for the provision of entering the industry. Growing fast development technology change within the electrical engineering field to was becoming a challenge these subjects. On the other side, the rapid growth of information and communication technology had been used to supporting in learning activities. This article was to reveal various problems and solutions. The descriptive content analysis was obtained by using literature review the articles published from 2011 to 2017. Based on the findings, this article offered a conceptual framework of elaboration developed strategies with the method teacher centered learning mixed the student centered learning to utilize Software as a Service (SaaS), as an alternative solution, which was expected to be developed into a model of learning.
\end{abstract}

Keywords : Power Electronics, Teaching and Learning, Descriptive, SaaS

\section{PENDAHULUAN}

Peran strategis pemerintah Indonesia dalam bidang pendidikan teknologi dan kejuruan adalah mencapai tujuan pendidikan secara utuh, yakni merubah dan meningkatkan pola pikir peserta didik yang berilmu pengetahuan, pola sikap yang ilmiah dan pola perilaku yang berketerampilan atau memiliki kompetensi tertentu.

Untuk dapat mencapainya, dibuatlah Kerangka Kualifikasi Nasional Indonesia (KKNI). KKNI pada dasarnya, menghendaki dan menuntut agar peserta 
didik mampu menguasai konsep atau teori, mampu berkomunikasi dan bekerjasama dengan baik serta mempunyai standar keahlian dan keterampilan atau skill tertentu dibidangnya. Untuk mendukung KKNI tersebut perlu dibuat kurikulum. Elemenelemen atau unsur-unsur penting dan utama dari terbentuknya sebuah kurikulum, diantaranya adalah adanya mata kuliah. Mata kuliah menjadi atribut atau penghubung antara dosen dan mahasiswa.

Mata kuliah elektronika daya merupakan sebuah mata kuliah wajib pada jurusan ataupun program studi dibidang teknik elektro dan atau elektronika, baik disiplin ilmu kependidikan maupun non kependidikan. Mata kuliah tersebut adalah cabang ilmu elektro yang mempelajari bidang aplikasi elektronika berkaitan dengan energi atau daya listrik.

Secara umum mata kuliah ini membahas sistem elektro dan elektronika, teori sirkuit, sistem dan teori kontrol, pemrosesan signal, elektromagnetik, simulasi dan komputer, mesin-mesin elektrik, sistem-sistem power dan fisik solid-state. Dapat dinyatakan bahwa bidang kajian ini termasuk memiliki konsep yang abstrak, terdapat banyak komponen elektronika, analisis hubungan antar rangkaian elektronika, melibatkan perhitungan atau kalkulasi matematika, ada juga pemograman komputer, analisis bentuk gelombang, muatan materi ajar yang kompleks dan dalam, bidang kajian yang meluas, adanya desain, termasuk mata kuliah yang di praktekkan dan juga melibatkan TIK.

Revolusi yang melanda dunia pendidikan sedang terjadi dengan terintegrasinya TIK kedalam pembelajaran (Radford, 2012). Beberapa contoh pengaruh atau integrasi tersebut adalah media pembelajaran berbasis elektronik (eLearning) seperti CD interaktif pembelajaran (Rukun, 2016) dan simulasi berbasis perangkat lunak Matlab/Simulink (Krismadinata, 2013).

Modernisasi eLearning seperti sistem manajemen perangkat lunak (software) pembelajaran (learning management system/ LMS) di masa depan adalah penggunaan atau pemanfaatan teknologi komputasi awan dengan model-model layanan infrastruktur (Infrastructure as a Service/laaS) sampai ke penyediaan perangkat lunak sebagai suatu layanan (Software as a service/SaaS) sangat menguntungkan terutama bagi institusi pendidikan tinggi (Ketel, 2014; Shereen, 2016; Mohammadi, 2014).

Tujuan penulisan artikel ini adalah untuk mengungkapkan berbagai macam masalah dan solusi pada mata kuliah elektronika daya. Metode yang dilakukan adalah studi literatur dengan analisis deskriptif.

Kenjangnya

perkembangan teknologi elektronika menjadi tantangan tersendiri dalam mengajarkan mata kuliah tersebut. Disisi lain bahwa laju dunia TIK telah turut digunakan sebagai upaya mendukung kegiatan pembelajaran .

Pada kesempatan ini, pembahasan dari kerangka konsep pengajaran dengan strategi elaborasi mengajar dan belajar memanfaatkan tools SaaS yang tersedia secara awan, coba untuk ditawarkan sebagai suatu solusi alternatif lain, yang diharapkan dapat dikembangkan menjadi model pembelajaran.

\section{Studi Literatur}

Mengajar adalah suatu ilmu dalam mendesain. Mengajar bukanlah ilmu roket. Ini jauh lebih sulit dari itu. IImu roket adalah tentang memindahkan atom dari a ke b; Mengajar adalah tentang memindahkan pola pikir (Laurillard, 2012).

Mengajar adalah konsep yang agak sulit dipahami dan cukup sulit untuk didefenisikan. Para ilmuwan dan peneliti dari berbagai disiplin ilmu telah menggunakan defenisi mengajar secara berbeda (Strauss, 2005). Mengajar dan belajar (teaching and learning) merupakan kegiatan yang terikat secara erat, sistematis dan memiliki prinsip-prinsip dalam rangka mencapai efektifitas dan efisiensi dalam meraih capaian pembelajaran (Dessus dkk, 2008).

Pembelajaran adalah proses dimana pengetahuan diciptakan melalui transformasi pengalaman (Kulturel-Konak dkk, 2013). Pembelajaran dapat didefenisikan sebagai pengaruh dari 
pengalaman pada perilaku (Houwer et.al, 2012).

Pembelajaran merupakan upaya yang dilakukan oleh pendidik dan peserta didik untuk dapat memperoleh tujuan dan capaian belajar sesuai dengan apa yang diharapkan. Pembelajaran yang benarbenar dapat merubah kondisi peserta belajar dari yang tidak mengetahui menjadi mengetahui, dari yang sudah mengetahui menjadi lebih dalam lagi pengetahuannya, dari yang kurang baik sikap atau perilakunya menjadi baik, dari yang telah baik sikap dan perilakunya menjadi semakin baik, yang tidak terampil menjadi terampil dan yang telah terampil menjadi semakin lebih terampil.

Seluruh aktivitas atau kegiatan yang terjadi antara pendidik, peserta belajar, materi ajar dan lingkungan pada situasi dan kondisi tertentu atau perkuliahan merupakan proses pembelajaran yang juga terkait dengan strategi.

Strategi pembelajaran adalah kegiatan atau aktivitas yang dilakukan oleh dosen dan mahasiswa agar dapat mencapai tujuan yang telah ditentukan. Desain strategi pembelajaran disusun dan disiapkan dalam suatu rencana perkuliahan yang biasanya selama satu semester. Strategi pembelajaran meliputi metode, teknik ataupun taktik yang diterapkan oleh dosen dan mahasiswa pada situasi dan kondisi tertentu didalam kelas secara tatap muka langsung maupun diluar kelas tidak tatap muka langsung (Crawford, 2005).

Strategi elaborasi merupakan suatu kegiatan yang dilakukan oleh pendidik untuk membantu siswa agar dapat membangun atau menghubungkan antara apa yang sudah mereka ketahui sebelumnya dan apa yang akan dipelajari selanjutnya. Dengan menggunakan strategi elaborasi, mereka dapat mengintegrasikan pemahaman baru dan lama dengan cara yang berarti sehingga menghasilkan suatu pemahaman yang lebih tinggi (Weinstein \& Hume, 1998).

Strategi elaborasi adalah aktivitas yang dilakukan dalam aspek kognitif yang menambah atau memperluas informasi yang sebelumnya tidak dimiliki oleh peserta didik, dengan cara mencocokkan, membuat analogi, membandingkan, meringkas, membangkitkan metafora, membuat pertanyaan, dan membentuk suatu model mental (Simsek \& Balaban, 2010).

Implementasi dari strategi elaborasi akan dapat membantu meningkatkan daya ingat (knowledge) peserta didik secara lebih lama (permanen). Pendidik harus mampu memberikan kesan positif dan praktis dari strategi elaborasi yang diterapkan, agar mahasiswa merasa senang dan nyaman dalam belajarmengajar. Strategi elaborasi dalam pembelajaran mudah untuk diterapkan dan berguna dalam berbagai situasi belajar (Weinstein \& Mayer, 1986).

\section{METODE}

Pencarian artikel sebagai bahan bacaan yang akan dijadikan tinjauan pada tulisan ini, bersumber dari situs:

http://ieeexplore.ieee.org/Xplore/home.jsp, http://www.sciencedirect.com/science/jour nals,

http://onlinelibrary.wiley.com/,

https://www.hindawi.com/journals,

http://www.springer.com/gp/

http://www.wiete.com.au/journals/GJEE/P ublish/index.html

Ketentuan dari kriteria seleksi situs yang di tetapkan adalah harus dari asosiasi dan atau institusi penyedia jasa penerbit artikel jurnal dan atau prosiding yang telah terakreditasi, bereputasi dan telah terindeks berskala internasional seperti SCOPUS. Kemudian melakukan penelusuran pada masing-masing basis data halaman web site (site visit) tersebut menggunakan kata kunci utama yang sama yakni: teaching power electronics. Kata kunci tambahan atau alternatif adalah learning power electronics, dan science education in power electronics. Dari penelusuran menggunakan operator boolean, diperoleh data awal pada IEEE sebanyak 178 artikel, ScienceDirect sebanyak 91 artikel, Wiley sebanyak 74 artikel, Hindawi sebanyak 1 artikel, Springer sebanyak 1 artikel dan Wiete sebanyak 1 artikel. Total data awal yang di peroleh sejumlah 346 artikel. 
Selanjutnya melakukan penyaringan (filter) untuk semua artikel dengan menetapkan ketentuan kriteria sebagai berikut:

a) tahun terbit artikel mulai dari 2011 sampai 2017

b) judul artikel harus terdapat salah satu kata seperti: power electronics, teaching/teach, instruction, learning, strategies, method, e-learning dan science education

c) pada abstrak menjelaskan secara singkat mengenai salah satu kata seperti: power electronics, teaching,

Tabel 1. Total artikel yang ditinjau

\begin{tabular}{clc}
\hline No & \multicolumn{1}{c}{ Institusi Penerbit Jurnal } & Jumlah \\
\hline 1 & IEEE & 32 \\
2 & ScienceDirect & 1 \\
3 & Wiley & 1 \\
4 & Hindawi & 1 \\
5 & Springer & 1 \\
6 & Wiete & 1 \\
Total & 37 \\
\hline
\end{tabular}

Dari total 37 artikel yang menjadi sumber bacaan untuk ditelaah, kebanyakan terbit ditahun 2015 sebanyak (9 artikel), tahun 2014 sebanyak (8 artikel), tahun 2013 sebanyak (7 artikel), tahun 2016 sebanyak (6 artikel), tahun 2012 sebanyak (4 artikel), tahun 2011 sebanyak (1 artikel) dan sampai pertengahan tahun 2017 sebanyak (1 artikel). Ada beberapa penulis yang memiliki lebih dari 1 artikel. Total data akhir ini diverifikasi kembali untuk memperoleh kepastian bahwa artikelartikel tersebut benar-benar memenuhi semua kriteria untuk dimasukkan dalam kajian dengan cara membaca ulang seluruh artikel tersebut. learning, e-learning dan innovation education in power electronics

d) artikel telah lolos tim peer-review, berbahasa Inggeris dan dapat didownload

Setelah dilakukan seleksi dan penyaringan, berdasarkan ketentuan kriteria artikel yang memenuhi persyaratan untuk kajian literatur, pada masing-masing database laman web site tersebut, telah diperoleh data akhir yang diperlihatkan pada tabel 1.

\begin{abstract}
Hasil yang ditemukan terhadap kajian artikel menjelaskan bahwa pembelajaran untuk mata kuliah elektronika daya, didapati banyak masalah dan tentu saja beragam solusi yang diberikan. Temuan dari studi literatur ini terdiri dari masalah-masalah dan solusisolusi.

Masalah-masalah tersebut seperti mengajar dan belajar yang kurang efektif dan efisien, rendahnya animo mahasiswa dalam mengikuti perkuliahan, rata-rata nilai mahasiswa yang masih tergolong rendah, banyaknya mahasiswa yang mengulang (remidial), sering menunda tugas, rendahnya motivasi belajar dan sebagainya. Semua masalah ditampilkan pada tabel 2 .
\end{abstract}

\section{HASIL DAN PEMBAHASAN}

Tabel 2. Masalah-masalah terkait mata kuliah elektronika daya

\begin{tabular}{lc}
\hline \multicolumn{1}{c}{ Nama Penulis } & Masalah-Masalah \\
\hline Anand, S., dkk, Ferreiro, A. & - Mahalnya biaya yang harus di keluarkan untuk membangun \\
L., dkk, Haque, E., dkk dan & laboratorium fisik elektronika daya dengan peralatan yang baik \\
Marek, J., dkk & - Metode pengajaran praktikum berbasis web secara virtual tidak \\
& memberikan pengalaman langsung dan terkadang salah \\
& menafsirkan eksperimen simulasi tersebut \\
Avotins, A., dkk, & - Durasi waktu yang terbatas pada sesi tatap muka pembelajaran \\
Bonho, S., dkk, Breard, A, & yang berlangsung di kelas dan di ruang laboratorium
\end{tabular}


dkk, Brioschi, R Cepeda, P., dkk, Jitngamkam, K., dkk, Simo, A., dkk, TrujilloAguilera, F. D., dkk

García, J., dkk, Haque, E., dkk, Vodovozov, V., dkk, Zhang, Z., dkk.

Hussain, I. S \& Jaafar S

Krosschell, J., dkk

Li, X., dkk

Martija, I., dkk, Martinez, F., dkk, Nedeljkovic, D, Rahman, M. M. A dan Raud, Z., dkk,

Maseda, F. J., dkk dan Tarateeraseth, $\mathrm{V}$

Muller, L., dkk

Musing, A \& Kolar, J. W

Rahman, M. M. A dan Tant, J., dkk

Rojko. A., \& Bauer, $P$

Trujillo-Aguilera, F. D., dkk

Trujillo-Aguilera, F. D., dkk
- Metode mengajar yang tradisional seperti ceramah, media powerpoint, e-learning multimedia dengan memutar CD dan pendekatan belajar yang berpusat pada pendidik

- Perkembangan TIK

- Penggunaan software Squirell dan mengajar berbasis elektronik (epedagogy)

- Sulitnya melakukan model pembelajaran untuk materi kuliah elektronika daya

- Rendahnya tingkat partisipasi peserta didik untuk berinteraksi, interaktiv dan interaktivity

- Kesenjangan kompetensi dan keterampilan yang di miliki

mahasiswa antara teori dan praktek

- Kesenjangan kemampuan soft skill dan hard skill

- Rendahnya nilai rata-rata mahasiswa untuk mata kuliah elektronika daya

- Mahasiswa kesulitan menyelesaikan proyek akhir atau skripsi

- Metode mengajar dengan pendekatan sistem uji kotak hitam (black box) yang selama ini di lakukan memiliki kelemahan dalam hal fleksibilitasnya

- Besarnya konsumsi energi listrik dan mahalnya biaya listrik pada alat kontrol analog catu daya yang di buat oleh perusahaan semikonduktor dan power supply yang terdapat di laboratorium

- Menurunnya motivasi dan minat belajar mahasiswa dari minggu ke minggu

- Sulitnya memahami materi atau topik bahasan yang abstrak pada elektronika daya

- Tingkat kegagalan mahasiswa yang tinggi terhadap mata kuliah elektronika daya

- Banyaknya materi dan kurikulum yang sudah usang

- Perkembangan teknologi elektronika daya yang semakin meluas

- Tuntutan menciptakan sumber daya manusia yang dapat memberikan solusi terhadap energi listrik (pembangkit listrik) yang bebas polusi dan aman untuk lingkungan di masa depan dengan mendalami materi kuliah sistem elektronika daya

- Mahasiswa masih jaring yang menguasai teknik sistem tertanam seperti penggunaan dan pemanfaatan perangkat keras dan perangkat lunak dalam satu paket (Arduino Uno)

- Keterbatasan pengetahuan, pengalaman dan minat peserta didik untuk pemograman teknologi kontrol digital

Belum tersedianya suatu fitur aplikasi simulator dalam pembelajaran elektronika daya

- Perkembangan teknologi generasi terbaru dari sistem berbasis elektronika daya sekarang ini harus berukuran lebih kecil, lebih ringan, lebih efisien misalkan kebutuhan listrik yang sedikit tetapi menghasilkan energi yang besar tanpa kipas pendingin tidak ada gangguan (EMI), gangguan sistem komunikasi, dll.

- Kurikulum harus dapat memastikan mahasiswa dapat membuat model, desain, dan mampu menerapkannya di dunia industri elektronika

- Metode mengajar tradisional seperti tatap muka di kelas dapat di gantikan dengan jarak jauh menggunakan dan memanfaatkan TIK

- Gaya belajar yang berbeda dari masing-masing mahasiswa

Belum tersedianya suatu alat penilaian terhadap penggunaan perangkat lunak dalam pembelajaran untuk kematangan proses belajar/mengajar pada mata kuliah elektronika daya

Melimpahnya informasi di era perkembangan TIK menimbulkan kebingungan untuk memperoleh kepastian dan kebenaran informasi yang di perolehnya tersebut 


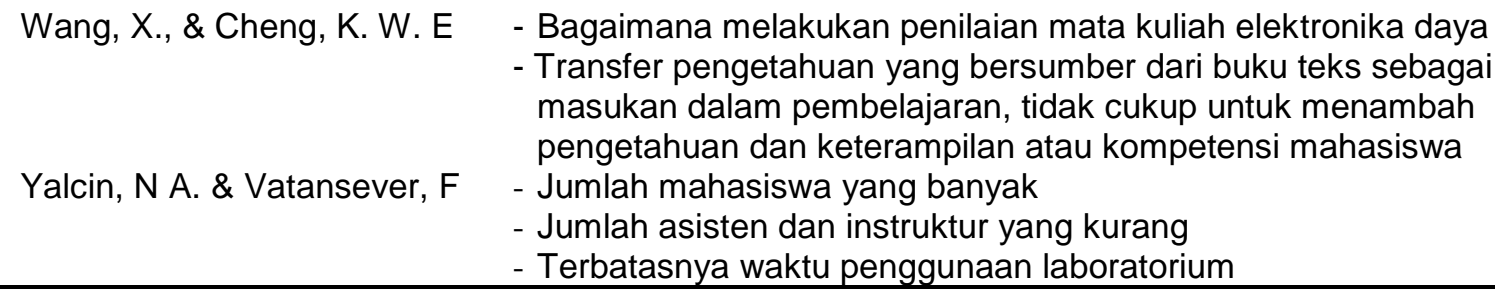

seperti berbasis proyek (project based learning/PjBL), pembelajaran berbasis masalah (problem based learning/ PBL), pengajaran berbasis do-it-yourself dan sebagainya. Semua solusi disajikan dan dirangkumkan pada tabel 3.

Tabel 3. Solusi-solusi pembelajaran mata kuliah elektronika daya

\begin{tabular}{|c|c|}
\hline Nama Penulis & Solusi-Solusi \\
\hline Anand, S., dkk & $\begin{array}{l}\text { Pengembangan metode Power Electronics and Drives Experimental Bench } \\
\text { (PEDEB) berbasis pengajaran "do-it-yourself" }\end{array}$ \\
\hline Avotins, A., dkk & PjBL dan PBL \\
\hline Bonho, S., dkk & PjBL dengan pendekatan multidisiplin \\
\hline Breard, A, & Simulasi dengan metode support vector regression (SVR) \\
\hline Brioschi, R & $\begin{array}{l}\text { Melakukan inovasi dalam metode mengajar dengan teori belajar meaningful } \\
\text { learning by David Ausubel yang di kombinasikan dengan teori belajar socio- } \\
\text { historical by Lev Vygotsky menggunakan multimedia (perangkat lunak Adobe } \\
\text { Flash CS5). }\end{array}$ \\
\hline Cepeda, P., dkk & $\begin{array}{l}\text { Simulasi dengan metode Fuzzy Logic, Adaptive Neurofuzzy Inference Systems } \\
\text { (ANFIS), dan algoritma genetika (GAs). }\end{array}$ \\
\hline Ferreiro, A. L., dkk & $\begin{array}{l}\text { Mengembangkan model pembelajaran berbasis laboratorium virtual (b-learning } \\
\text { model) }\end{array}$ \\
\hline García, J., dkk & $\begin{array}{l}\text { Menggunakan PjBL dengan sintak: } \\
\text { 1. Membagi kelompok kerja yang heterogen, presentasi dan penugasan } \\
\text { 2. Menjelaskan materi } \\
\text { 3. Melakukan seminar dan simulasi } \\
\text { 4. Memberikan proyek dan penilaian }\end{array}$ \\
\hline Haque, E., dkk & $\begin{array}{l}\text { Penerapan laboratorium virtual berbasis web melalui internet dengan antarmuka } \\
\text { LabVIEW dan MATLAB }\end{array}$ \\
\hline Hussain, I. S \& Jaafar S & $\begin{array}{l}\text { Menggabungkan metode ceramah dan PBL, dengan pendekatan student center } \\
\text { learning }\end{array}$ \\
\hline Jitngamkam, K., dkk & $\begin{array}{l}\text { Melakukan kombinasi mengajar dengan metode ceramah, percobaan dan } \\
\text { simulasi. }\end{array}$ \\
\hline Krosschell, J., dkk & $\begin{array}{l}\text { Mengembangkan model pembelajaran PEGO (Power electronics to GO). PEGO } \\
\text { terdiri dari dua blok modular yakni teori dan praktek. Modul teori untuk } \\
\text { perkuliahan berbasis desain dan modul praktek dengan PjBL }\end{array}$ \\
\hline Li, X., dkk & Pengajaran berbasis virtual learning environment \\
\hline Marek, J., dkk & $\begin{array}{l}\text { Kombinasi Learning management system (LMS) menggunakan Moodle, } \\
\text { eLearning interaktif "Power MOSFET" dan simulasi } 3 \text { dimensi (3-D TCAD). }\end{array}$ \\
\hline Martija, I., dkk & Pengajaran berbasis simulasi \\
\hline Martinez, F., dkk & $\begin{array}{l}\text { Kombinasi PjBL, cooperative lerning tipe jigsaw, pembelajaran berbasis } \\
\text { percobaan dan penilaian menggunakan portfolios dan rubrik }\end{array}$ \\
\hline Maseda, F. J., dkk & PjBL dan simulasi \\
\hline Muller, L., dkk & Pengajaran berbasis Arduino Uno \\
\hline Musing, A \& Kolar, J. W & LMS, GeckoCIRCUITS dan simulator \\
\hline Nedeljkovic, D & Pengajaran berbasis self-assesment dan forecasts \\
\hline Rahman, M. M. A & PjBL dan PBL \\
\hline Raud, Z., dkk & Pengajaran dengan peta konsep menggunakan software CmapTools \\
\hline
\end{tabular}


Rojko. A., \& Bauer, P.

Simo, A., dkk

Tant, J., dkk

Tarateeraseth, V

Trujillo-Aguilera, F. D., dkk

Vodovozov, V., dkk

Wang, X., \& Cheng, K. W.

E

Yalcin, N A. \& Vatansever, $\mathrm{F}$

Zhang, Z., dkk
LMS Moodle, Blackboard dan eCampus berbasis multimedia interaktiv dan virtual laboratories

Metode tradisional (tatap muka langsung di kelas) di kombinasikan Lotus Learning Management System (LLMS)

Simulasi dengan package PLECS for Matlab/Simulink dan membuat proyek prototipe alat

Pengajaran berbasis percobaan

Learning Content Management System (LCMS), simulasi dan evaluasi

LCMS yang dikombinasikan dengan strategi pelatihan

Melakukan metode pengajaran berbasis hasil (Outcome Based Learning) dengan cara percobaan di lab

Virtual based learning dengan mengembangkan enam modul pengajaran untuk materi yang berbeda yang di gunakan pada kelas teori dan praktek

PjBL yang di kombinasikan dengan ceramah, konten interaktif, penulisan laporan dan praktikum
Tulisan ini tidak membahas mengenai hasil kajian literatur, namun difokuskan pada solusi apa yang dapat diberikan setelah kajian dilakukan. Solusi yang dikemukakan dibawah ini yang akan menjadi topik pembahasan.

Mengajar dan belajar yang baik dan efektif mengharuskan mahasiswa untuk berperan aktif dalam pembelajaran (Kertiasih dkk, 2015). Jika mahasiswa tidak tahu bagaimana belajar dan menggunakan berbagai strategi belajar, maka akan sulit bagi mereka untuk mendapatkan keuntungan dari pengajaran, tidak peduli seberapa baik pengajaran atau pedoman tersebut telah direncanakan atau dilaksanakan. Pembelajaran dapat membuat frustasi dosen dan mahasiswa.

Confucius (551-479 SM) mengatakan bahwa Apa yang Saya dengar dan Saya akan Lupa (I hear and I forget), Apa yang Saya Lihat dan Saya akan Ingat (I see and I remember), Apa yang Saya Lakukan dan Saya akan Mengerti ( $I$ do and I understand).

Siswa belajar dengan berbagai cara seperti melihat dan mendengar, menghafal dan memvisualisasikan, mengingat dan bernalar logis, membuat analogi dan melakukan atau bertindak. Pendidik harus memvariasikan desain strategi pengajaran dengan berbagai metode untuk merelasikan cara belajar dan karakteristik mereka (Felder \& Brent, 2005; Kipper \& Ruutmann, 2011).

Strategi elaborasi merupakan strategi belajar-mengajar yang disandarkan pada teacher center learning/TCL dan student

$\begin{array}{llr}\text { center learning/SCL } & \text { dengan } \\ \text { mengintegrasikan } & \text { TIK } & \text { dalam } \\ \text { pembelajaran. } & & \end{array}$

TCL merupakan metode mengajar yang fokus pada dosen sebagai pelaku utama dalam aktivitas membelajarkan. Metode TCL terdiri dari tiga tahapan utama yaitu: membuka, menyajikan dan menutup. Pada pembukaan perkuliahan, dosen menyampaikan salam dan menunjuk satu orang mahasiswa untuk dapat memimpin doa pembuka.

Pada tahap menyajikan dibagi menjadi tiga kegiatan inti, yakni: eksplorasi, pembimbingan dan konfirmasi. Kemudian mendata kehadiran mahasiswa. Pada tahap penyajian, dosen menjelaskan capaian pembelajaran dari mata kuliah yang diampu, memaparkan seluruh struktur materi atau bahan ajar termasuk memberikan buku text utama dan tujuan belajar dari setiap materi yang disajikan, melakukan tinjauan singkat tentang apa yang akan dipelajari, memberikan penugasan, kontrak perkuliahan, aplikasi software utama yang digunakan dan menjelaskan sistem penilaian.

Ketika melakukan metode ceramah, penjelasan, seminar dan atau demonstrasi, mahasiswa telah membaca materi dirumah. Setiap mahasiswa diminta untuk menuliskan poin-poin yang dianggap penting dan baru. Metodemetode lain yang dilakukan adalah menampilkan video, aplikasi simulasi, pemodelan dan multimedia interaktif presentasi. Pada saat ice break, dapat menggunakan taktik stand-up komedi.

Taktik lain yang dilakukan dengan 
membagi mahasiswa menjadi berkelompok, terdiri dari 3-4 mahasiswa yang heterogen, memberikan penugasan kelompok berupa proyek yang harus diselesaikan, memberikan penugasan individu (home work), latihan dan tanyajawab. Pada tahap penutup, dosen menegaskan kembali apa yang telah dipelajari dan mengingatkan untuk materi selanjutnya. Kemudian menunjuk satu orang mahasiswa untuk memimpin doa penutup.

Metode SCL merupakan pendekatan belajar-mengajar yang berpusat pada aktivnya mahasiswa dalam melakukan pembelajaran (active-learner-centered) secara mandiri, independen dan autonom. SCL merupakan metode belajar yang fokus pada mahasiswa sebagai pelaku utama dalam pembelajaran. Metode dan teknik atau taktik lain yang digunakan pada SCL seperti berbagi opini, kolaborasi, mencari isu atau topik pembicaraan terkini, discovery, inquiry, pemberian proyek kerja tim dan pemberian masalah.

Dosen berperan sebagai fasilitator atau tutor. Interaksi, komunikasi, diskusi dan kegiatan lainnya terjadi via internet. Dosen mewajibkan mahasiswa untuk log/sign in ke sistem manajemen pembelajaran awan (cloud learning management system/CLMS) berbasis SaaS.

SaaS merupakan suatu model layanan pada teknologi komputasi awan yang dapat diakses dengan mudah melalui suatu jaringan internet, dengan antar muka berbasis web yang dapat diakses dari multi platform komputer, dari mana saja dan kapan saja, tanpa membutuhkan proses instalasi. SaaS pada dasarnya merupakan perangkat lunak yang dihostingkan dan disediakan sebagai suatu layanan server (Ma \& Kauffman, 2014; Tan \& Sun, 2013).

SaaS yang disarankan pada tulisan ini adalah GoConqr. GoConqr dipilih karena memiliki fitur mind maps, flowchart, flashcards dan beragam jenis Quizzes (Yahfizham dkk, 2017). Alamat web sitenya dapat dikunjungi di https://www.gocongr.com. Desain kerangka konsep strategi elaborasi dengan metode TCL dan SCL dengan tools SaaS, seperti tampilan gambar di bawah ini:

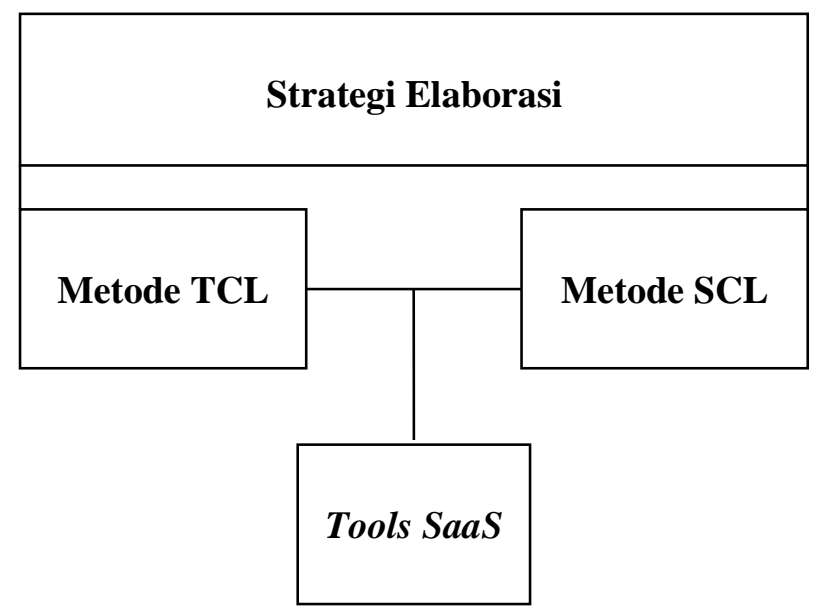

Gambar 1. Kerangka konsep strategi elaborasi, metode TCL dan SCL dengan tools SaaS.

\section{SIMPULAN DAN SARAN}

Studi literatur menjelaskan bahwa mengajar dan belajar untuk mata kuliah elektronika daya, ternyata memiliki keunikan tersendiri dan juga tantangan yang manarik akibat dari pengaruh percepatan teknologi elektro, elektronika dan teknologi informasi dan komunikasi. Pendidik seperti dosen harus mampu memberikan pengalaman yang baik dalam menjalankan pembelajaran sehingga 
terjadi suatu peningkatan kemampuan mahasiswa secara kognitif, afektif dan psikomotorik.

Pengalaman pembelajaran dibangku perkuliahan semestinya harus dapat membuat mahasiswa menerapkan dan mengimplemen- tasikan pengetahuan, sikap dan keterampilan atau skill yang diperolehnya menjadi bahagian dalam kehidupan sehari-hari. Desain kerangka konsep strategi elaborasi yang ditawarkan dalam pembelajaran untuk mata kuliah elektronika daya diharapkan akan dapat diimplementasikan menjadi suatu pengembangan model pembelajaran yang baku yang dapat teruji validitas, praktikalitas dan efektivitasnya.

\section{DAFTAR PUSTAKA}

Anand, S., et al. 2012. Unique Power Electronics and Drives Experimental Bench ( PEDEB ) to Facilitate Learning and Research. IEEE, 55 (4): 573-579.

Avotins, A., et al. 2013. A Project-Based Learning Approach to Improve Quality of Power Electronic Courses. Methodologies and processes for education. IEEE. 80-85.

Bonho, S., et al. 2015. Teaching Power Electronics With Engineering Interdisciplinary Projects. IEEE. 1-6.

Breard, A. 2016. Metamodel of Power Electronic Converters Using Learning SVR Method Coupling With Wavelet Compression. IEEE, 58(2): 588-598.

Brioschi, R. 2015. Educational Innovation In Power Electronic's Education With Multimedia's Resources: Production And Implications In Education Practice. IEEE. 1-6.

Cepeda, P., et al. 2014. Simulation to Implementation as Good Practices for Teaching Power Electronics to Undergraduate Students: Fuzzy Sliding Mode Control for DC Motors. Hindawi Publishing Corporation. 1-9.

Crawford, A., et al. 2005. Teaching and Learning Strategies for the Thinking Classroom. The IDEA.
Dessus, P., et al. 2008. What is Teaching ?. ICHSL. 6:49-55.

Felder, R. M \& Brent, R. 2005. Understanding Student Differences. Journal Engineering Education. 94(1): 57-72.

Ferreiro, A. L., et al. 2015. A B-Learning New Approach Applied to a Practical Power Electronics Converters Course. IEEE. 1-8.

García, J., et al. 2013. "Laboratory": A Project-Based Learning Example On Power Electronics. IEEE. 754-760.

Haque, E., et al. 2015. Implementation of Remote Laboratory for Engineering Education in the field of Power Electronics and Telecommunications. IEEE. 19-22.

Haque, E \& Ahmed, F. 2016. A Pragmatic Approach for Quality Enhancement in Classroom Teaching of Engineering Education in Developing Countries: A Case Study on Power Electronics. IEEE. 349-354.

Houwer, D. J., et al. 2012. What is Learning ? on the Nature and Merits of a Functional Definition of Learning". Journal In Press. Psychonomic Bulletin \& Review. 1-36.

Hussain, I. S. 2016. Linking Knowledge and Industry Needs through Problembased Learning in Power Electronics Course. IEEE. 16-21.

Jitngamkam, K., et al. 2016. PowerElectronics Learning through experiment and simulation: DC-DC converters. IEEE. 403-408.

Karayaka, H. B \& Adams, R. 2015. The evaluation of a new hybrid flipped classroom approach to teaching power electronics. WIETE. Global Journal of Engineering Education, 17(2): 61-69.

Kertiasih, N. K., dkk. 2015. Pengembangan Sistem Evaluasi Untuk Dosen Sebagai Upaya Peningkatan Kualitas Pembelajaran. JPTK, UNDIKSHA, 12(1): 27-34.

Ketel, M. 2014. E-Learning In a Cloud Computing Environment. IEEE, pp. 01.

Kipper, H., \& Ruutmann, T. 2011. Effective Teaching Strategies For Direct And Indirect Instruction In Teaching 
Engineering Implemented At Tallinn University Of Technology, 36: 60-75.

Krismadinata., et al. 2013. Photovoltaic Module Modeling Using Simulink/Matlab. Procedia Environ. Sci., 17: 537-546.

Krosschell, J., et al. 2015. PEGO Powerpack: A modular power electronics learning platform. IEEE. 15.

Kulturel-Konak, S., et al. 2013. Assessing Professional Skills in STEM Disciplines. IEEE. 7-10.

Laurillard, D. 2012. Teaching as a Design Science. Building Pedagogical Patterns for Learning and Technology. Routledge. Taylor \& Francis.

Li, X., et al. 2013. A Virtual Laboratory for Power Electronics and DSP Based Motion Control. IEEE. 1-8.

Ma, D. \& Kauffman, R. J. 2014. Competition Between Software-as-aService Vendors. IEEE, 61(4): 717729.

Marek, J., et al. 2014. Power MOSFET interactive e-Learning course. IEEE. 120-123.

Martija, I., et al. 2013. Functional Dissection of Power Electronic Systems as Learning Technique. IEEE. 11-15.

Martinez-rodrigo, F., et al. 2017. Using PBL to Improve Educational Outcomes and Student Satisfaction in the Teaching of $D C / D C$ and $D C / A C$ Converters. IEEE. 1-9.

Maseda, F. J., et al. 2014. An Active Learning Methodology in Power Electronic Education. IEEE. 0-4.

Mohammadi, S. \& Emdadi, Y. 2014. ELearning Based on Cloud Computing. International Journal of Basic Sciences \& Applied Research, 3(11): 793-802.

Muller, L., et. al. 2015. Using the Arduino Uno to Teach Digital Control of Power Electronics. IEEE. 1-8.

Musing, A \& Kolar, J. W. 2014. Successful Online Education-Gecko CIRCUITS as Open-Source Simula tion Platform. IEEE. 821-828.

Nedeljkovic, D. 2012. Forecasts and Results of Written Exams at Courses of Control Engineering for Students of Power Engineering. IEEE. 988-992.

Radford, A. W. 2012. Learning at a Distance, Under graduate Enrollment in Distance Education Courses and Degree Programs. STATS IN BRIEF. 1-22.

Rahman, M. M. A. 2016. Project Based Teaching of Power Electronics in Undergraduate Power System Course. IEEE. 200-204.

Rahman, M. M. A. 2016. Incorporating Advanced Power Electronic Concepts with Hands-on Emphasis in a Lowcost Power Engineering Curriculum. IEEE. 178-181.

Raud, Z., et al. 2013. Concept Maps in Power Electronics Education. IEEE. 280-285.

Rojko. A., \& Bauer, P. 2014. Education in power electronics based on remote resources. IEEE. 839-844.

Rukun, K., et al. 2016. Rancang Bangun CD Interaktif Pembelajaran Pengolahan Citra Digital Berbasis Multimedia Dengan Model Classic Tutorial. JANAPATI, 5(2): 50-60.

Shereen, A. G. R. F. 2016. Application Of Cloud Computing Based On ELearning Teaching Tool. IJRET, 269271.

Simo, A., et al. 2015. Current Practices in E-learning: A Case Study for Electrical Power Engineering in Higher Education. Procedia-Soc. Behav. Sci., 191: 605-610.

Simsek, A \& Balaban, J. 2010. Learning Strategies of Successful and Unsuccessful University Students. Contemporary Educational Technology, 1(1): 36-45.

Strauss, S. 2005. Teaching as a natural cognitive ability: Implications for classroom practice and teacher education. Developmental Psychology and Social Change. 368-388.

Tan, C., Liu, K. \& Sun, L. 2013. A Design Of Evaluation Method For SaaS In Cloud Computing. Journal of Industrial Engineering and Management, 6(1): 50-72.

Tant, J., et al. 2012. Power Electronics for Electric Vehicles: a Student Laboratory Platform. IEEE. 1-7. 
Tarateeraseth, V. 2014. Educational Laboratory Experiments on EMC in Power Electronics. IEEE, 3(3): 55-60.

Trujillo-Aguilera, F. D., et al. 2012. On the evaluation stage for new Power Electronics multimedia interactive tools. IEEE. 1-4.

Trujillo-Aguilera, F. D., et al. 2013. Towards student wellness in the new teaching/learning process of Power Electronics. IEEE. 319-322.

Trujillo-Aguilera, F. D., et al. 2014. Stepping into a new Learning Environment: from Virtual to Personal. Power Electronics case study. IEEE. 836-840.

Vodovozov, V., et al. 2014. Development of Students' Activity through OnLecture Assessment in Electrical Engineering. IEEE. 2213-2217.

Wang, X \& Cheng, K. W. E. 2013. Design method of outcome based learning for an inverter experiment in a Power Electronics Subject. IEEE. 1-5.

Weinstein, C. E. \& Hume, L. M. 1998. Study Strategies for Lifelong Learning. APA.
Weinstein, C. E \& Mayer, R. E. 1986. The teaching of learning strategies. Handbook of Research on Teaching, New York: Macmillan, 315-327.

Yahfizham., F. Purwani, K. Rukun, and Krismadinata, 2017. A Review of Cloud Learning Management System (CLMS) Based on Software as a Service (SaaS). IEEE, 205-210.

Yalcin, N. A \& Vatansever, F. 2015. "A Web-Based Virtual Power Electronics Laboratory. Wiley Periodicals, Inc.7178.

Yang, X., et al. 2011. Strengthening the "Power Electronics" Course Teaching, Focusing on Students' CapacityBuilding. Springer. International Conference, CSE. 465-471.

Zhang, Z., et al. 2015. Teaching Power Electronics with a Design-Oriented, Project-Based Learning Method at the Technical University of Denmark. IEEE.1-7. 